\title{
Credit Scoring for M-Shwari using Hidden Markov Model
}

\author{
Ntwiga, Davis Bundi \\ Weke Patrick \\ School of Mathematics, University of Nairobi, Nairobi, Kenya \\ doi: 10.19044/esj.2016.v12n15p176 URL:http://dx.doi.org/10.19044/esj.2016.v12n15p176
}

\begin{abstract}
The introduction of mobile based Micro-credit facility, M-Shwari, has heightened the need to develop a proper decision support system to classify the customers based on their credit scores. This arises due to lack of proper information on the poor and unbanked as they are locked out of the formal banking sector. A classification technique, the hidden Markov model, is used. The poor customers' scanty deposits and withdrawal dynamics in the M-Shwari account estimate the credit risk factors that are used in training and learning the hidden Markov model. The data is generated through simulation and customers categorized in terms of their credit scores and credit quality levels. The model classifies over 80 percent of the customers as having average and good credit quality level. This approach offers a simple and novice method to cater for the unbanked and poor with minimal or no financial history thus increasing financial inclusion in Kenya.
\end{abstract}

Keywords: Hidden Markov, credit score, credit quality, M-Shwari, poor and unbanked

\section{Introduction}

The unbanked and poor people lack good financial options as their income is volatile, often fluctuating daily, and without reliable ways of pushing and pulling money between good and bad days (FSD, 2015). Few banks have been willing to build the costly infrastructure needed to collect low value cash deposits. However, a rapid advancement in electronic mobile phone transactions has dramatically increased in Kenya. In the year 2007, MPesa ("M" for mobile and "Pesa' is money in Swahili), a mobile phone based money transfer system was introduced by Safaricom Kenya (Safaricom is Kenya's leading mobile phone telecommunication company) and has continued to grow at a fast pace in the country. M-Pesa has become one of 
the most successful mobile phone based financial services in the developing world (Jack and Suri, 2011).

A survey by Deesai (2012) lists Kenya as one of the countries where there are more mobile money accounts than deposit accounts with commercial banks. Research shows that the poor seek to accumulate their savings to pay for life-cycle events, as it offers day-to-day cash management system (Mbiti and Wei, 2011). The use of M-Pesa is mostly limited to transferring money from individual to individual, with minimum saving pattern by the users. The service is popular and based on already existing infrastructure, thus low expansion and handling costs. The service users have each cut a niche depending on their needs. It is on this background that $\mathrm{M}$ Shwari, ("Shwari" means calm in Swahili), a micro-credit product of Safaricom Kenya and the Commercial Bank of Africa (a registered commercial bank operating in Kenya) was started in November 2012. MShwari, based on M-Pesa platform was started to capture both the banked and unbanked in an effort to increase financial inclusion. The product is based on mobile phone offering a combination of savings and access to a micro-credit loan.

The features of M-Shwari are highlighted by Cook and Mckay (2015): allows customers to save and access credit; account maintenance is free; cost of moving money between M-Pesa and M-Shwari is free; no transfer of funds between M-Shwari and a bank account, only between MShwari and M-Pesa, then M-Pesa to a bank account; and credit scoring algorithm used for accessing a loan on M-Shwari is based on a set of telecommunication variables from Safaricom data related to M-Pesa transactions, airtime credit and length of time as a customer. The duo further observes that earlier adopters of M-Shwari are more likely to be urban, already banked and those above the poverty line. The features of credit scoring algorithm for M-Shwari highlighted by Cook and Mckay (2015) limit the ability of the poor to access the micro-credit facility due to limited resources. Challenges remain on how M-Shwari is able to capture credit quality of the poor and unbanked with scanty mobile phone usage. They are limited to deposit average cash in their accounts, with minimal usage of airtime and other services offered by the telecommunication company, Safaricom.

In this paper, we propose a decision support system based on Hidden Markov model (HMM) that classifies the M-Shwari poor and unbanked customers according to three credit quality levels as poor, average and good (PAG). The decision system is based on the scanty deposits and withdrawals in the customers M-Shwari accounts. We are interested in those below the poverty line, unbanked and with income that is fluctuating and volatile. This is to cover the existing gap on the mechanism used by Safaricom in the credit 
scoring of M-Shwari customers. The HMM is a classification model that can consolidate the deposit and withdrawals, estimate an observation probability and classify the customer into credit groups according to their risk (Benyacoub, Bernoussi and Zoglat, 2014). In credit scoring, an application scoring system summarizes all applicant information onto one overall value measuring the credit worthiness of a loan applicant (Ntwiga and Weke, 2016).

\section{Related Work}

M-Pesa users have relatively high opportunity costs of holding funds on their phones (Mbiti and Weil, 2011). Introduction of M-Shwari as in-built function in M-Pesa service has given the saving pattern of M-Pesa users a new impetuous. Users are now able to save with a possibility of an access to a micro-credit loan, promoting individual outcomes (FSD, 2010). In the financial sector, lending is an important element of financial intermediation, which is itself at the heart of an economy financial architecture. Therefore, M-Shwari could offer a relief and the way out to micro-credit challenges due to lack of information of the unbanked and the poor (Deesai, 2012).

The collateral process in Kenya fails to protect the lenders and conveys little benefit to borrowers (FSD, 2009). The legal environment for the collateral shows a highly fragmented system for credit bureaus being limited due to information asymmetry. The law emphasizes on sharing negative information but do not insist on positive information. Berger and Frame (2005) observes that banks can increase information available by collecting necessary information by use of technology. As Kenya's mobile network and mobile banking continue to advance, information sharing infrastructure can enhance financial inclusion (FSD, 2009; Davel, Serakwane and Kimondo, 2012).

A study by Ivatury and Pickens (2006) observes that perceptions about banking, m-banking and technology determine the rate of adoption as income alone is not a sufficient indicator. Ntwiga (2016b) notes that 25 percent of the adult population in Kenya does not have access to any form of financial services. The study found that an individual is more likely to use a mobile phone followed by an informal group, a bank, Savings and credit organizations and then a Micro-Finance institution for financial services. Therefore, a mobile phone is commonly used in Kenya to access financial services. A need still exists to explore how to assist the low-income segment of the market to access financial services to better enhance financial inclusion and lower this adult population excluded from the services. MShwari can cover this gap. Studies on micro-credit facilities observe that a positive change in income is observable when the poor use these facilities (Ahlin and Jiang, 2005; Chavan and Ramakumar, 2002). A key pointer is the 
poor to save and access credit as this brings an economy from stagnation to full development. The ability to accumulate savings is critical to assist the poor benefit from micro-credit program (Ahlin and Jiang, 2005).

The HMM has the capabilities to capture the saving patterns through the customer deposits and withdrawals in the M-Shwari account and estimate the credit quality level of each customer. Mohammad and Assal (2016) notes that HMM is the most frequently used technique in speech based automatic identity recognition system due to its versatility. A model for customer relationship dynamics for the effect of encounters between the customer and the firm on customer-firm relationship and the customer's choice behavior is modeled using HMM (Netzer, Lattin and Srinivasan, 2008). A model for the occurrence of defaults within a bond using HMM is the work of Crowder, Davis and Giampieri (2005). Srivastava, Kundu, Sural and Majumdar (2008) modeled a credit card transaction processing sequence by a stochastic process emitted by an HMM. This approach drastically reduced the number of false positive transactions, identified as malicious by a fraud detection system even though they were actually genuine.

The study of Hassan and Nath (2005) applied HMM in stock market forecasting and showed 100 percent accuracy in the prediction. The HMM is a dynamic tool that can detect a sudden downgrading of a customer credit worthiness. Quirini and Vannucci (2014) observe that dynamic tools are essential to assess credit risk in order to gain profitability in the complex and fluctuating credit market. Mhamane and Lobo (2012) study the online banking fraud and found that automated banking reduces the costly paper handling, manual teller interaction and save on time from our busy schedule. They cautioned on the increase in fraud associated with online transactions.

The work of Robert, Raphael, Paul and Glenn (1996) is on credit risk and credit scoring with emphasis on delinquent and default cases. A borrower's credit history is summarized by a credit history score which is a strong predictor of loan delinquency. Earlier credit history assessment was subjective but introduction of a statistically derived measure of the credit risk increased the observable probability of default. Bucay and Rosen (2000) developed a simulation based framework to estimate the one period credit loss in a retail loan portfolio. The usefulness of the model was demonstrated by estimating a one-year credit loss. The study showed that some refinement in the modeling of portfolio risk may lead to the greater improvement in credit risk management.

The micro-laws that govern the dynamics of agents in a social group and the driving force behind social evolution are extensively studied (Chen, Goldberg, Malik and Wallace, 2008). Social network analysis helps to collect and study the structure of the social dynamics which delves on the behavior of the agents. Daniel and Grissen (2015) used behavioral 
signatures in mobile phone data to predict default with accuracy than the approach of credit scoring using financial histories. The method was found to be promising even for the poor borrowers whose mobile phone usage is also very sparse. The algorithm reduces defaults by 41 percent while still accepting 75 percent of the borrowers.

Insights on how the poor and unbanked that lack financial history can benefit from the use of social media or network data in credit scoring is presented in Ntwiga and Weke (2016). The duo noted that the approach can offer an alternative in consumer credit scoring and lending process as social network data continues to grow as more and more people are joining the networks for communication. The use of social network data for credit scoring using the HMM is the work of Ntwiga (2016). The social data in the study is based on trust, distrust, gender, age, interactions rate, relationship levels, among other social factors. The HMM parameters are estimated from the network using the singular value decomposition. HMM captures the dynamics of the credit scores and credit classification of the obligors in a social network. A dynamic threshold is estimated to detect the likely default rates in the loan portfolio.

The social data insights are important in our study though we will not use the social data in this work. We are interested in using the M-Shwari account activities of the poor and unbanked in terms of their scanty deposits and withdrawals. The data is used to estimate the credit scores and classify the customers into the three credit quality levels, poor, average and good. This would provide a mechanism that M-Shwari can use to offer or deny a customer a micro-credit loan.

\section{Hidden Markov Model}

We classify M-Shwari customers based on their credit scores as captured by use of their deposits, withdrawals, saving ratio, duration of money in the account, account balance and the frequency of deposits and withdrawals based on account activity dates. We refer to them as credit scoring factors (CSF). Due to the low amount and frequency of deposits and withdrawals, the customers have to run the accounts for a period of six months to offer enough data to capture their credit worthiness. In general, the CSF are basically derived from the deposits and withdrawals of the customer from the M-Shwari account.

We have assumed that they deposit amounts of less than one dollar at any given time as these customers are assumed to be poor and living below the poverty line. The M-Shwari system can detect these poor customers by coding the system to detect amounts below one dollar and mark them as transactions for the poor and unbanked. The CSF are estimated through simulation and form the entries of a real-valued matrix which are 
decomposed with the singular value decomposition to estimate the variables necessary for HMM learning and training. A transition matrix $A_{2 \times 2}$ has high and low values for the customers and the observation matrix $B_{2 \times 3}$ has the three credit quality levels (poor, average and good). The transition and observation matrices are derived from the historical data of the customers using the CSF. A HMM can be characterized by the following: number of states in the model, state transition probabilities, observation probability distribution that characterizes each state, initial state distribution, and the observation symbols (Rabiner, 1989)

1) The number of states $(M=2)$ in the model with the set of states denoted as $S=\left\{S_{1}, S_{2}\right\}=\{$ High, Low $\}$

2) The state transition probability distribution

$A=\left\{a_{i j}\right\}$ where $a_{i j}=P\left[q_{t+1}=S_{j} \mid q_{t}=S_{i}\right], 1 \leq i, j \leq M, t=1,2 \ldots, T$

3) The number of distinct observation symbols $(K=3)$ per state. We denote the set of observation symbols corresponding to the physical output of the system being modeled as $V=\left\{v_{1}, v_{2}, v_{3}\right\}=\{$ Poor, Average, Good $\}$

4) The observation symbol probability matrix

$B=\left\{b_{j}(k)\right\}$, where $b_{j(k)}=P\left[v_{k} \mid S_{j}\right], 1 \leq j \leq M, 1 \leq k \leq K$

5) The initial state probability vector

$\pi=\left\{\pi_{i}\right\}$ where $\pi=P\left[q_{1}=S_{i}\right], 1 \leq i \leq M$

We use the notation $\lambda=(A, B, \pi)$ as the set of parameters of the model

\section{Singular Value Decomposition}

The singular value decomposition (SVD) is a matrix factorization method that has been used widely in different applications ever since an efficient algorithm for its computation was developed. SVD is a powerful and important technique in matrix computations and analysis as it reduces high dimensional and highly variable set of data to a lower dimensional space that exposes the substructure of the original data more clearly (Carla and Mason, 2012; Ntwiga, 2016). The low rank matrix factorization method is widely employed in various applications such as collective filtering and document clustering (Tang, $\mathrm{Hu}$ and Liu, 2014). SVD has a variety of applications in ecology, engineering, chemistry, geology, biomedical, scientific computing, geophysics, (Soman, Soumya and Soman, 2009), in social networks (Ntwiga, Weke, Manene and Mwaniki, 2016a; Ntwiga, Weke, Manene and Mwaniki, 2016b) and many other areas.

Let $D$ be a $N \times M$ real valued matrix of the customers' deposits in a given time period, $t$. The matrix $D$ can be represented as the product of two 
orthonormal matrices $U$ and $V$ and a diagonal matrix $S$. We express the matrix $D$ as

$$
D=U_{N \times N} S_{N \times K} V_{K \times M}
$$

The columns of $U$ are the eigenvectors of $D D^{T}$, and the columns of $V$ are the eigenvectors of $D^{T} D$. The singular values on the diagonal of $S$ are the square roots of the nonzero eigenvalues of both $D D^{T}$ and $D^{T} D$, which are ordered decreasingly. The best rank one approximation by the SVD is used (See Carla and Mason, 2012; Ntwiga et al, 2016a; Ntwiga et al, 2016b)

$$
\left\|D-V V^{T} D^{T}\right\|_{2}
$$

The columns of $V$ are the eigenvectors generated from the columns of matrix $D$. Dynamics of the matrix from the column perspective are contained in $V$ and are used to estimate the deposit ratings of each customer for a given time period. The data is scaled in the interval $(0,1]$ to estimate the individual customer parameters for the HMM training and learning.

\section{Credit Scoring}

The probabilistic relationship between M-Shwari customer account activities and the credit scores as well as the credit quality level are based on the emissions from the HMM. The classifications offer insights on who among the poor and unbanked clients have strong credit worthiness and those very weak to qualify for a micro-credit loan.

Let $\beta_{i}^{t} \leq 1$ be the credit score of customer $i$ at time period $t$. We express $\beta=P\left(O_{1}, O_{2}, \ldots, O_{\tau} \mid \lambda\right)$ as the credit score from the observations for the last six months. This is the initial score that is expected to change at each time period $t$. The first six months forms the time period $t=1$ and time increment is observed from the seventh month $(t=2)$, eighth month $(t=3)$ and so on. Let $\alpha_{i}^{t}$ be the credit quality level of customer $i$ at time period $t$, where $\alpha=\{$ Poor, Average, Good $\}$. The estimation of the credit quality level is based on the credit score which is emitted directly by the HMM. We compute the average credit score of the customers and partition the customers into two groups, that is, those below and those above the average credit score, $\bar{\alpha}$. The matrices $A$ and $B$ for the transition and observation respectively are then extracted to form the respective HMM notations

$$
\lambda_{u}=\left(A_{u}, B_{u}, \pi_{u}\right) \text { and } \lambda_{l}=\left(A_{l}, B_{l}, \pi_{l}\right)
$$

for the respective upper and lower group of customers. The two notations estimate the respective values of $\beta_{u}$ and $\beta_{l}$. This is to enable us classify the 
clients into the three credit quality levels. The $\beta_{l}$ and $\beta_{u}$ forms the interval to classify the customers into the three credit quality levels

$$
\alpha= \begin{cases}P, & \text { If } \beta \leq \beta_{l} \\ A, & \text { If } \beta_{l}<\beta<\beta_{u} \\ G, & \text { If } \beta \geq \beta_{u}\end{cases}
$$

The credit quality levels are dynamic as the threshold is based on $\beta$ that depends on M-Shwari account activities. We do not have benchmark data set available for this study and simulation from uniform distribution is implemented to test the system. We assume that each poor customer has an equal chance of emitting any of the three credit quality levels, poor, average and good.

\section{Results}

We compare the credit scores of the customers against the upper and lower dynamic threshold to classify the customers as having poor, average or good credit quality level. Figure 1 shows that most of the customers are in the average credit quality level. The credit scores of the customers shows high levels of dynamism as depicted in figure 1. Classification into the credit quality levels is based on the lower and upper threshold values. The credit scoring is derived from the scanty withdrawal and deposit frequencies in the M-Shwari customer account. Even among this group of customers, we have those whose deposits and withdrawals can offer insights on their financial behavior and be a basis for micro-credit lending.

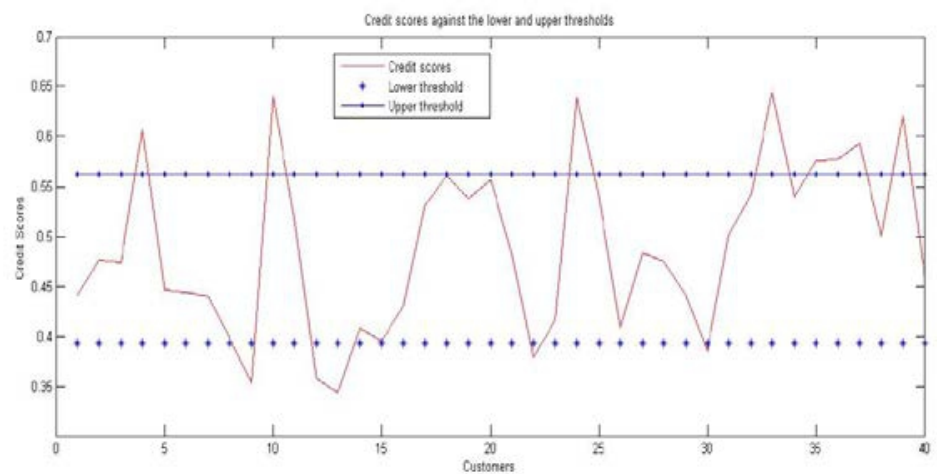

Figure 1: The credit scores of the customers partitioned into three groups of poor, average and good credit quality levels based on the lower and upper threshold.

Figure 2 shows the dynamics observable from the classification of the customers into the three credit quality levels. Most of the customers appear in the average credit quality level. The classifications in figure 2 and figure 1 do not require a lot of resources either on Safaricom Kenya side or the poor and unbanked customers. The HMM capture the dynamics of deposits and 
withdrawals even though they are scanty and emit the credit worthiness of the customers. The classifications in figure 2 are estimated in a similar manner to those in figure 1 based on the two threshold values.

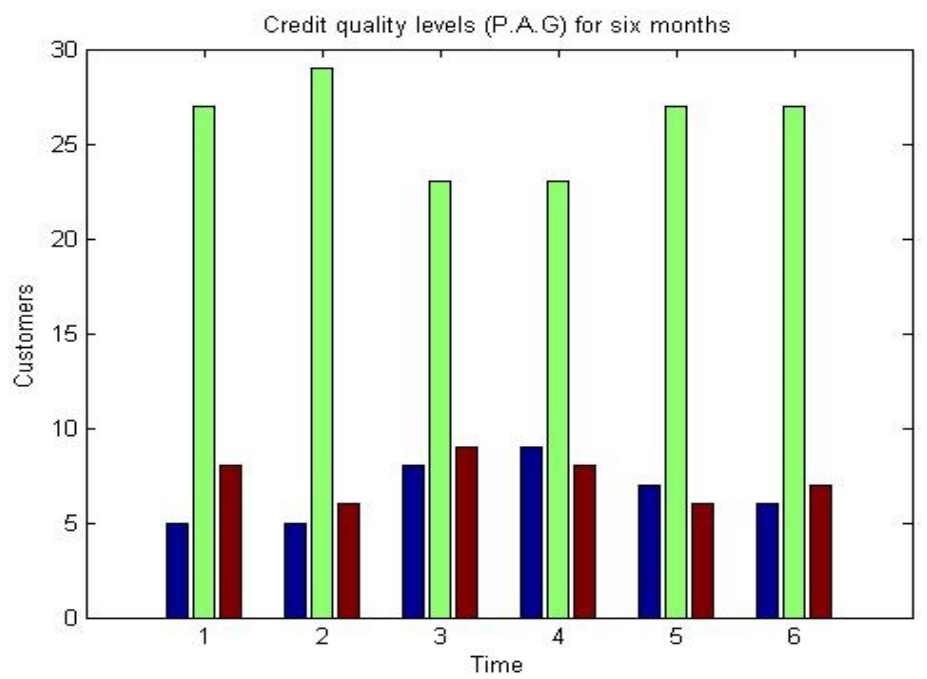

Figure 2: The credit quality levels (P.A.G) tracked for a period of six months

Figure 3 indicates that the credit scores of the customers tend to a normal distribution as the number of customers increases. The analysis is for a group of 500 customers for a period of four months $(t=1,2,3,4)$. We recall that the initial simulation was drawn from the uniform distribution and it tends to converge to a normal distribution. The results compares well to those in table 1 and table 2.
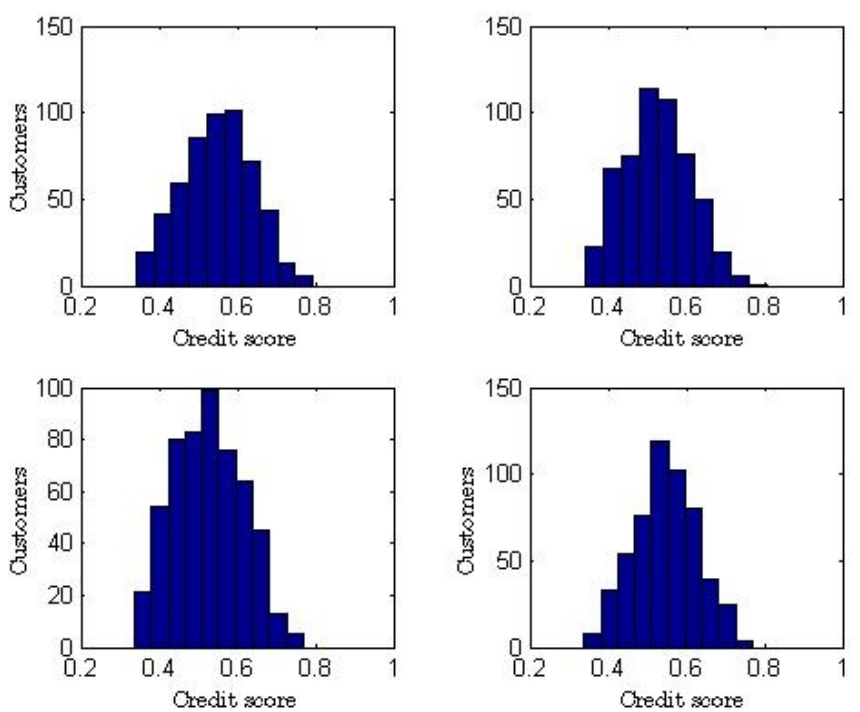

Figure 3: Credit Scores of 500 customers from four consecutive time periods 
The majority of the customers are in the credit quality level of average and good as depicted in table 1. Different sets of customers' credit scores are classified into poor, average and good for a period of one year and then the mean is computed. Table 1 show that over 80 percent of the customers would qualify for a loan if the average and good credit quality level is considered as a baseline for credit lending. Irrespective of the number of customers, around 52.5 percent to 60.9 percent are in the average credit quality level at any given time period (See table 1 and figure 2 for comparison).

Table 1: Mean credit score for the period of one year

\begin{tabular}{|c|c|c|c|}
\hline Customers & Poor & Average & Good \\
\hline 20 & 0.163 & 0.567 & 0.271 \\
\hline 50 & 0.160 & 0.525 & 0.315 \\
\hline 80 & 0.190 & 0.599 & 0.212 \\
\hline 120 & 0.165 & 0.606 & 0.230 \\
\hline 200 & 0.198 & 0.585 & 0.217 \\
\hline 300 & 0.179 & 0.609 & 0.211 \\
\hline 500 & 0.194 & 0.591 & 0.215 \\
\hline
\end{tabular}

Table 2 highlights the credit quality level dynamics observed for different sets of customers for a period of six months. Generally, over 80 percent of the customers in most of the cases are in the average and good credit quality levels. The dynamics of the credit quality classification are observable in table 1 , figure 2 and table 3.

Table 2: Credit quality classification (in percent) of customers for a period of six months

\begin{tabular}{|c|c|c|c|c|c|c|c|c|c|}
\hline \multirow{2}{*}{$\begin{array}{c}\text { Time } \\
\text { (Months) }\end{array}$} & \multicolumn{3}{|c|}{ 20 Customers } & \multicolumn{3}{c|}{ 40 Customers } & \multicolumn{3}{c|}{ 120 Customers } \\
\cline { 2 - 10 } & $\mathrm{P}$ & $\mathrm{A}$ & $\mathrm{G}$ & $\mathrm{P}$ & $\mathrm{A}$ & $\mathrm{G}$ & $\mathrm{P}$ & $\mathrm{A}$ & $\mathrm{G}$ \\
\hline 1 & 0.15 & 0.55 & 0.30 & 0.13 & 0.68 & 0.20 & 0.21 & 0.57 & 0.22 \\
\hline 2 & 0.10 & 0.65 & 0.25 & 0.13 & 0.73 & 0.15 & 0.22 & 0.59 & 0.2 \\
\hline 3 & 0.15 & 0.65 & 0.20 & 0.20 & 0.58 & 0.23 & 0.20 & 0.58 & 0.23 \\
\hline 4 & 0.15 & 0.70 & 0.15 & 0.23 & 0.58 & 0.20 & 0.19 & 0.62 & 0.20 \\
\hline 5 & 0.05 & 0.70 & 0.25 & 0.18 & 0.68 & 0.15 & 0.20 & 0.60 & 0.20 \\
\hline 6 & 0.05 & 0.75 & 0.20 & 0.15 & 0.68 & 0.18 & 0.23 & 0.52 & 0.25 \\
\hline
\end{tabular}

The variations in the number of customers in each credit quality level in table 2 shows that the majority of the customers classified as average and good in terms of their credit quality level that are derived from the credit scores. The minimum deposits and withdrawals can be harnessed and captured through a classification method with an aim to capture the credit scores of the poor and unbanked. 


\section{Conclusion}

The scanty deposits and withdrawals of the poor and unbanked customers can be used in credit scoring when the appropriate techniques like hidden Markov models are used. The method is simple, versatile and dynamic as the changing conditions in the market are reflected in the deposits and withdrawals and in turn captured by the model. This decision support system can assist in increasing financial inclusion by capturing a section of the 25 percent of the adults in Kenya with no access to financial services. The analysis shows that over 80 percent of the poor and unbanked can qualify for the micro-credit loan if the lower threshold is the minimum credit score for lending. The poor and unbanked should be incorporated in the micro-credit facility of M-Shwari but with special consideration to allow them to deposit the low and scanty amounts of money they have.

Our work invites an extension to analyze the optimal amounts to lend given the deposits and withdrawals of the customers. Further, how M-Shwari can be made more relevant by the poor and unbanked by introducing peer group members borrowing as this increase repayment rates among the members.

\section{References:}

Ahlin, C., and Jiang, N. (2005). Can micro-credit bring development? Unpublished manuscript, working paper No. 02-W19, Department of Economics, Vanderbilt University, Nashville

Benyacoub, B., Bernoussi, S., and Zoglat, A. (2014). Building classification models for customer credit scoring. Working paper, University of Mohamed V-Agdal, Morocco

Berger, A.N., and Frame, S.C. (2005). Small business credit scoring and credit availability. Working paper series 10, Federal Reserve Bank of Atlanta, USA

Bucay, N., and Rosen, D. (2000). Applying portfolio credit risk models to retail portfolios. The Journal of Risk Finance, 2 (3): 35-61

Carla, D.M., and Mason, A.P. (2012). The extraordinary SVD. Unpublished manuscript, arVix:1103:2338v5

Chavan, P., and Ramakumar, R. (2002). Micro-Credit and rural poverty: An analysis of empirical evidence. Economics and Political Weekly, 37 (10): 955-965

Chen, H., Goldberg, M., Malik, M., and Wallace, W. (2008). Reverse engineering: An agent based hidden Markov model for complex social systems. International Journal of Neural Systems, World Scientific Publishing Company, 1-24 
Cook, T., and Mckay, C. (2015). How M-Shwari works: The story so far. Access to Finance Forum No. 10 (Reports by Consultative Group to Assist the Poor and Financial Sector Deepening), Nairobi, Kenya

Crowder, M., Davis, M., and Giampieri, G. (2005). A hidden Markov model of default interaction. Quantitative Finance, 5 (2): 27-34

Daniel, B., and Grissen, D. (2015). Behavior revealed in mobile phone usage predict loan repayment. Unpublished manuscript, Department of Economics, Brown University, USA

Davel, G., Serakwane, T., and Kimondi, M. (2012). Kenya credit information sharing initiative: A progress report 2008-2011, challenges and opportunities. Financial Sector Deepening, Nairobi

Deesai, S. (2012). Mobile money for the unbanked: State of the industry, GSMA, Dubai

Financial Sector Deepening (FSD). (2015). Two steps back: How low income Kenyans think about and experience risk in their pursuit of prosperity. Financial diaries, Nairobi, Kenya [www.fsdkenya.org]

Financial Sector Deepening (FSD). (2010). Financial capability and the poor: Are we missing the mark? Bankable Frontier Associates, Issue 2, Nairobi, Kenya [www.fsdkenya.org]

Financial Sector Deepening (FSD). (2009). Costs of collateral in Kenya: Opportunities for reform. Growth Fin, Nairobi, Kenya [www.fsdkenya.org] Hassan, R., and Nath, B. (2005). Stock market forecasting using hidden Markov model: A new approach. Proceedings of the $20055^{\text {th }}$ International Conference on Intelligent Systems Design and Applications

Ivatury, G., and Pickens, M. (2006). Mobile phone banking and low income customers: Evidence from South Africa. Consultative Group to Assist the Poor and World Bank, Washington

Jack, W., and Suri, T. (2011). Mobile money: The economics of M-Pesa. Unpublished work, George Town University and MIT Sloan

Mbiti, I., and Weil, D.N. (2011). Mobile banking: The impact of M-Pesa in Kenya. Working paper 17129, National Bureau of Economic Research, Cambridge

Mhamane, S., and Lobo, L.M.J. (2012). Fraud detection in online banking using hidden Markov model. International Conference on Information and Network Technology. IPCSIT, 37

Mohammad, A.M.A., and Assal, A.M.A. (2016). Automatic identity recognition using speech biometric. European Scientific Journal, 12 (12): 43-63

Netzer, O., Lattin, J.M., and Srinivasan, J.M.L. (2008). A hidden Markov model of customer relationship dynamics. Marketing Science, 27 (2): 185204 
Ntwiga, D.B. (2016a). Social network analysis for credit risk modeling. Unpublished PhD thesis, School of Mathematics, University of Nairobi, Kenya

Ntwiga, D.B. (2016b). Financial inclusion and cream skimming in Kenya's financial sector. International Journal of Research in Finance and Marketing, 6 (1):41-46

Ntwiga, D.B., and Weke, P. (2016). Consumer lending using social media data. International Journal of Scientific Research and Innovative Technology, 3 (2): 1-8

Ntwiga, D.B., Weke, P., Manene, M., and Mwaniki, J. (2016a). Modeling trust in social network. International Journal of Mathematical Archive, 7(2):64-68

Ntwiga, D.B., Weke, P., Manene, M., and Mwaniki, J. (2016b). Trust and distrust: A reputation ratings approach. International Advanced Research Journal in Science, Engineering and Technology, 3 (2): 111-114

Quirini, L., and Vannucci, L. (2014). Creditworthiness dynamics and hidden Markov models. Operational Research Society, 65: 323-330

Rabiner, L.R. (1989). A tutorial on hidden Markov models and selected application in speech recognition. Proceedings of the Institute of Electrical and Electronics Engineers, 77(2): 257-286

Robert, B.A., Raphael, W.B., Paul, S.C., and Glenn, B.C. (1996). Credit risk, credit scoring, and the performance of home mortgages. Federal Reserve Bulletin

Soman, S.T., Soumya, V.J., and Soman, K.P. (2009). Singular value decomposition. International Journal of Recent Trends in Engineering, Academy Publisher, 1 (2)

Srivastava, A., Kundu, A., Sural, S., and Majumdar, A.K. (2008). Credit card fraud detection using hidden Markov model. IEEE Transactions on Dependable and Secure Computing, 5 (1)

Tang, J., Hu, X., and Liu, H. (2014). Is distrust the negation of trust? The value of distrust in social media. Association of Computing Machinery, 9781-4503-2954-5/14/09, Santiago, Chile 